\title{
Construction of Aluminum Alloy Constitutive Model Based on BP Neural Network and the Study of Non- isothermal Hydroforming
}

Xiao Jing Liu ( $\sim$ lxj812@126.com )

Harbin University of Science and Technology

Xue Feng Ma

Harbin University of Science and Technology

Chao Li

Harbin University of Science and Technology

Jin Qin

Harbin University of Science and Technology

\section{Peng Chen}

Harbin University of Science and Technology

\section{Research Article}

Keywords: Constitutive model, BP neural network, non-isothermal hydroforming, numerical simulation

Posted Date: April 28th, 2021

DOl: https://doi.org/10.21203/rs.3.rs-454068/v1

License: (9) This work is licensed under a Creative Commons Attribution 4.0 International License. Read Full License 


\title{
Construction of Aluminum Alloy Constitutive Model Based on BP Neural Network and the
}

\section{Study of Non-isothermal Hydroforming}

\author{
Xiao Jing Liu* Xue Feng Ma·Chao Li·Jin Qin·Peng Chen
}

\begin{abstract}
With the continuous development of high-end technology in aerospace and automotive, in order to meet the needs of high performance, high precision and lightweight of parts, the materials used are lightweight and strong, but very difficult to deform, so it is difficult to obtain high-quality, high-precision parts. In order to improve the forming quality and precision of parts, taking 6061-T6 aluminum alloy cylindrical cup with spherical bottom as the research object, the non-isothermal hydroforming process is studied by combining numerical simulation with experiment. The key of numerical simulation technology lies in the accuracy of simulation, which depends on the establishment of a suitable rheological stress relationship. So, a constitutive model that can truly reflect the thermoforming characteristics of 6061-T6 aluminum alloy materials is established through a uniaxial tensile test and BP neural network. Applying the constitutive model to the study of numerical simulation of non-isothermal hydroforming, the cylindrical cup with spherical bottom with high quality is obtained through the optimization of non-isothermal process parameters. After experimental verification, the results of numerical simulation are highly compatible with the actual forming results of parts, and have high reliability.
\end{abstract}

Keywords: Constitutive model, BP neural network, non-isothermal hydroforming, numerical simulation

\section{Introduction}

With the continuous development of high-end technology in aerospace and automotive, the shape of various automotive components has become more complex, and some parts have been unable to achieve forming performance under normal stamping. At present, because of their low density and higher strength, aluminum alloy materials have gradually become the focus of research in aerospace and automotive[1,2]. However, due to plasticity restrictions, some parts are difficult to form precisely under complex stress states, which with complex surfaces or small fillets at the bottom, and often have problems such as rupture and wrinkle.

In order to improve the forming performance of parts, domestic and foreign scholars have developed some new forming process, one of which is the Hydrodynamic Deep Drawing, that is, using the liquid chamber instead of the die, under the pressure of liquid in the liquid chamber, the blank is firmly attached to the punch during the downing process of the punch until it $\overline{\text { Xiao Jing Liu(*).Xue Feng Ma·Chao Li·Jin Qin·Peng Chen }}$ School of Materials Science and Engineering, Harbin University of Science and Technology, 150040 Harbin, China e-mail: maxuefeng_98@163.com is formed. With the further development of this process, a large number of forming methods have been derived by controlling different process parameters, such as applying independent radial hydraulic pressure, using double layered blank, and utilizing a combined floating and static die cavity (HDDC), effectively improving the forming limit, precision and forming quality of parts[35]. Another method is the Thermoforming Process of aluminum alloy, mainly used in the 5 series aluminum alloy of low-strength, the production of many parts has been applied to the automotive industry [6-8]. The combination of thermoforming and hydrodynamic deep drawing has the advantages of these two advanced manufacturing techniques, that is, improving the performance of the material and having excellent forming effect on the precision of complex parts $[9,10]$.

In this paper, 6061-T6 aluminum alloy material is selected, its constitutive model is established, the forming law is analyzed by numerical simulation, and the optimal forming parameters are selected for test verification. A constitutive model is established through a uniaxial tensile test and BP neural network, which can reflect the temperature deformation characteristics of 6061-T6 aluminum alloy materials, 
and the model is applied to numerical simulation. The forming simulation is carried out in parallel between the hydroforming deep drawing and the non-isothermal hydroforming of the cylindrical cup with spherical bottom. Using the cavity pressure as the variable, the optimal cavity pressure curve is obtained by controlling the size of the cavity pressure to analyze the wall thickness distribution of the forming part. Then on this basis, by controlling the non-isotherms between the punch and the blank to explore the optimal temperature loading, providing guidance for the machining of such parts.

\section{Uniaxial tensile test}

A thermal tensile test is carried out using the MTS universal electronic testing machine (as shown in Figure 1). The chemical composition of the blank is shown in Table 1, where wt is the mass fraction.
The experiment selected 6061-T6 aluminum alloy blank with thickness of $2 \mathrm{~mm}$. According to the requirements of GB6395-86, the scale of tensile specimen is shown in Figure 2 and the specimen is shown in Figure 3. The test was conducted at three tensile rates of $10^{-1}, 10^{-2}, 10^{-3}$, and each tensile rate is tested 6 times at different temperatures. In order to ensure the reliability of the test results, three tests were carried out on the test pieces at the same temperature and at the same tensile rate, and the median value was determined to be valid. In order to ensure the uniform temperature in the furnace of the MTS universal electronic testing machine, the furnace temperature is heated to the desired temperature for drawing, and the temperature is expected to be maintained for one hour, then the furnace is opened and the sample is held, and then the temperature of the furnace is raised to the target temperature insulation for 5 minutes to begin the tensile test [11].

Tab.1 Chemical composition of 6061-T6 aluminum alloy

\begin{tabular}{cccccccccc}
\hline Element & $\mathrm{Si}$ & $\mathrm{Mg}$ & $\mathrm{Fe}$ & $\mathrm{Cu}$ & $\mathrm{Mn}$ & $\mathrm{Cr}$ & $\mathrm{Zn}$ & $\mathrm{Ti}$ & $\mathrm{Al}$ \\
\hline Content $/ \mathrm{wt} \%$ & 0.6 & 1.0 & 0.7 & 0.28 & 0.15 & 0.20 & 0.25 & 0.15 & 96.67 \\
\hline
\end{tabular}

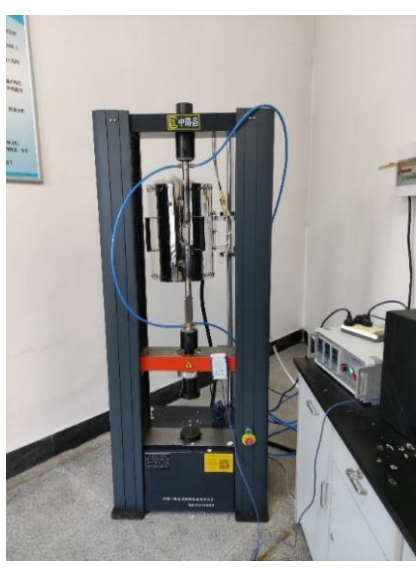

Fig. 1 MTS universal electronic testing machine

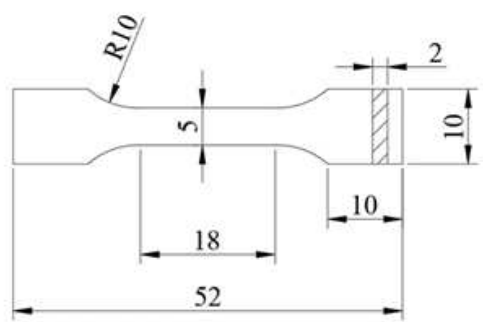

Fig.2 scale of tensile specimen

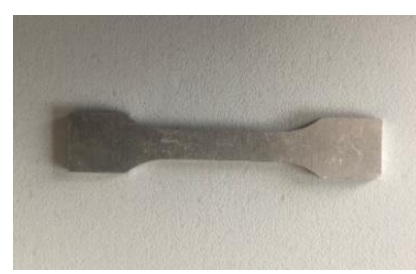

Fig. 3 The tensile specimen

The results of the tensile of 6061-T6 with a strain rate of $0.1 \mathrm{~s}-1$ at different temperatures are shown in Figure 4, from top to bottom, it is $25^{\circ} \mathrm{C}, 50^{\circ} \mathrm{C}, 100^{\circ} \mathrm{C}, 150^{\circ} \mathrm{C}, 200^{\circ} \mathrm{C}$, and $250^{\circ} \mathrm{C}$.

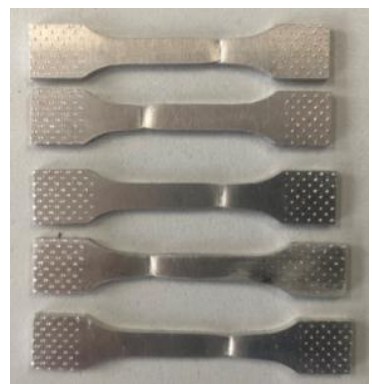

Fig. 4 Specimen with a strain rate of $0.1 \mathrm{~s}^{-1}$ at different temperatures

(The temperature is $25,50,100,150,200$, and 250 from top to bottom) 
In order to solve the construction equation, the experimental data of the thermal uniaxial tensile test need to be converted to the true stress strain curve, as follows [12]:

The engineering stress on is converted as:

$$
\sigma_{n}=\frac{F}{S_{0}}
$$

Where $\mathrm{F}$ is the load applied to the blank, $\mathrm{S}_{0}$ is the initial area of the specimen.

The engineering strain $\varepsilon \mathrm{n}$ is converted as:

$\varepsilon_{n}=\frac{\Delta l}{l_{0}}$

Where $\Delta l$ is the distance between the gauge length, $l_{0}$ is the amount of elongation between the gauge length.

The interval between the gauge length is extended from $l$ to $l+\Delta l$ during specimen drawing, the amount of change is $d l$, so the amount of strain change

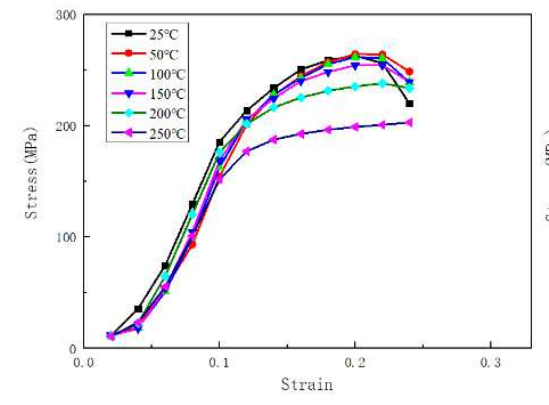

(a) $\dot{\varepsilon}=10^{-1}$

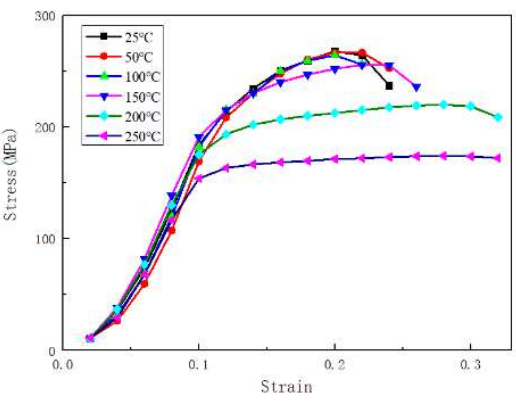

(b) $\dot{\varepsilon}=10^{-2}$

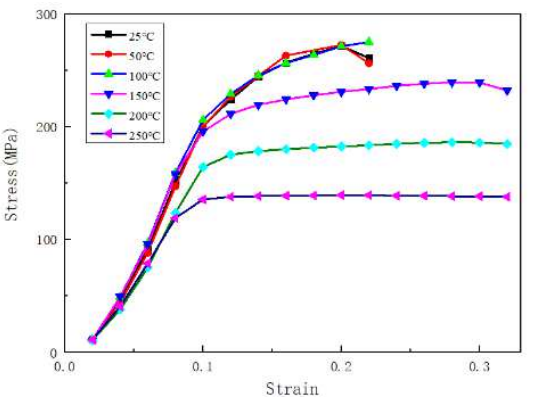

(c) $\dot{\varepsilon}=10^{-3}$

Fig. 5 The true stress-strain curve at different strain rates

As can be seen from Figure 5, the 6061-T6 has poor plasticity and lower limit strain value at room temperature. When the temperature reaches $150^{\circ} \mathrm{C}$, the plasticity change is not obvious, the limit strain value is increased by $17 \%$ relative to room temperature, but at this time the intensity begins to decrease. when the temperature reached $250^{\circ} \mathrm{C}$, the plasticity increased significantly, and the limit strain value was increased by $50 \%$ compared to room temperature. When the temperature is $200^{\circ} \mathrm{C}$ to $250^{\circ} \mathrm{C}$, the softening of 6061 T6 aluminum alloy flow is obvious [13-14], and the plasticity is strong in this temperature range. At a certain temperature, with the increase of strain rate, strain hardening becomes faster, tensile strength becomes larger, and elongation rate is decreases.

\section{Build neural network model}

is converted as:

$d \varepsilon=\frac{d l}{l}$

Solve $\varepsilon$, and it is determined as follow:

$\varepsilon=\int \frac{d l}{l}=\ln l-\ln l_{0}=\ln \frac{l}{l_{0}}$

Available in association with formula 2, $\varepsilon$ can be determined as follow:

$\varepsilon=\ln \left(1+\varepsilon_{n}\right)$

Because of the principle of constant volume:

$A l=A_{0} l_{0}$

Linked-up, the stress $\sigma$ is shown as follow:

$\sigma=\sigma_{n}\left(1+\varepsilon_{n}\right)$

The original stress strain data is converted using formula 7, which obtained by the universal electronic testing machine, and the true stress-strain curve at different strain rates is shown in Figure 5. 
from the uniaxial tensile test, the floating range of the data is relatively large, and in order to facilitate the calculation, the data need to be normalized and organized into a certain area. In this paper, the max-min standardization is used for normalization, and it is for class $a$ is normalized, as shown as follows:

$$
Y=0.1+0.8 \times \frac{a x-\min a}{\max a-\min a}
$$

Where $Y$ is the normalized data, $\min a$ is the minimum value in class $a$, and $\max a$ is the maximum value. The temperature and stress of uniaxial tensile test are normalized by using this method.

Due to the strain rate changes greatly, using this normalization method results in a large difference between the data, which affects accuracy. Therefore, the method shown in formula 9 is used.

$\dot{\varepsilon}=\frac{\left(3+\lg \dot{\varepsilon}-0.95\left(3+\lg \dot{\varepsilon}_{\min }\right)\right)}{1.05\left(3+\lg \dot{\varepsilon}_{\max }\right)-0.95\left(3+\lg \dot{\varepsilon}_{\min }\right)}$

\subsection{The selection of parameter}

This article selects the structure of the single hidden layer. The number of neuron nodes in the hidden layer is usually determined by empirical formulas. As shown in formula 10 .

$$
\delta=\sqrt{m+n}+a
$$

Where $\delta$ is the neuron node, $m$ is the input node, $n$ is the output node, $a$ is the adjustment parameter and $a \in[1 \sim 10]$.

This paper explores the constitutive relation in the warm state of 6061-T6 aluminum alloy, the main factors are temperature $T$, strain $\varepsilon$, strain rate $\dot{\varepsilon}$, and stress $\sigma$.The temperature $T$, the strain $\varepsilon$ and the strain rate $\dot{\varepsilon}$ are used as inputs, and the stress $\sigma$ is output. That is, $m=4, n=1, a=4$, and the number of hidden nodes $\sigma=6$.

A total of 342 data sets were participating, with 85 per cent training data and 15 per cent test data. After the simulation run, the target accuracy is set to $1 * 10^{-3}$, the learning rate to $1 * 10^{-3}$, and the maximum times of learning is 1100 .

\section{3 determination of the transfer function and the processing of the results}

The transfer function uses the Sigmoid function, whose function definition is shown as follows:

$$
f(x)=\frac{1}{1+e^{-x}}
$$

The input form is: $n e t=x_{1} \omega_{1}+x_{2} \omega_{2}+x_{3} \omega_{3}+\cdots+x_{n} \omega_{n}$

The Sigmoid function output is :

$y=f(n e t)=\frac{1}{1+e^{-n e t}}$

The conductor output of the Sigmoid function is:

$$
f^{\prime}(n e t)=\frac{1}{1+e^{-n e t}}-\frac{1}{\left(1+e^{-n e t}\right)^{2}}=y(y-1)
$$

The S-type function and derivative curve are shown in Figure 7.

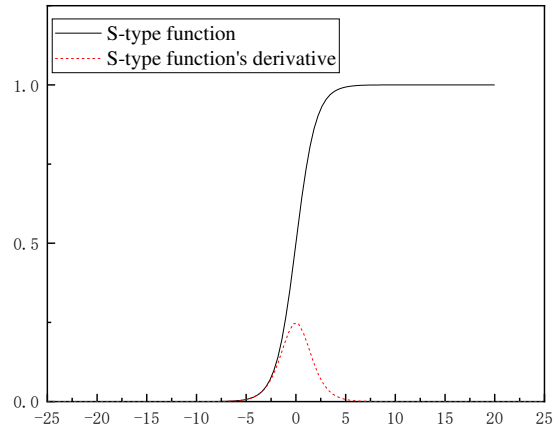

Fig.7 S-type function and its derivative curve

As can be known from Figure 7, its derivative is positive at net $\in(-5,0)$ and the value is getting larger. This shows that the value of $f(x)$ is getting larger and the growth rate too. But its derivative is positive at net $\in(0,5)$, the value is getting smaller. Explain that the value of $f(x)$ is getting larger but the growth rate is slowing. In order to facilitate the neural network training in this paper, the net should be controlled within the fast convergence interval.

In order to facilitate the neural network's processing of data, the input data is normalized, so it is necessary to reverse the stress $\sigma$ processing of the output [17]. The reverse processing formula is shown as follows.

$\sigma=\sigma_{\min }+1.25\left(\sigma_{\mathrm{n}}-0.1\right)\left(\sigma_{\max }-\sigma_{\min }\right)-(15)$

Where $\sigma$ is the predicted true stress value, $\sigma_{\max }$ is the maximum value in the stress test sample, and $\sigma_{\min }$ is the minimum value in the stress test sample. $\sigma_{\mathrm{n}}$ is the stress value after normalization. the correlation curve between the neural network prediction value and the true value is shown in Figure 8, where the fitting coefficient $\mathrm{R}$ is 0.9991 , which means the fit is good. 


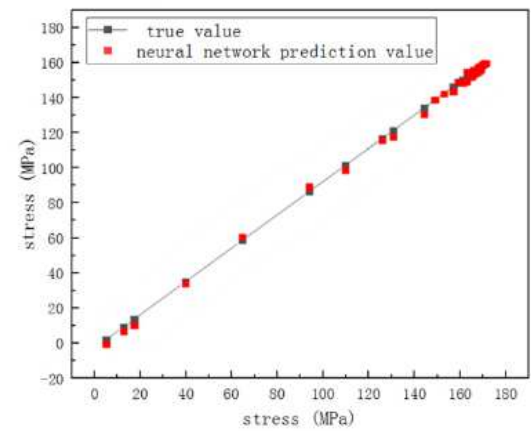

Fig. 8 Correlation curve

\subsection{Comparison of forecast results}

The true stress-strain curve from the uniaxial tensile test is compared with the stress strain predicted by the BP neural network model at different strain rates and temperatures, the results are shown in Figures 9,11 and 12.

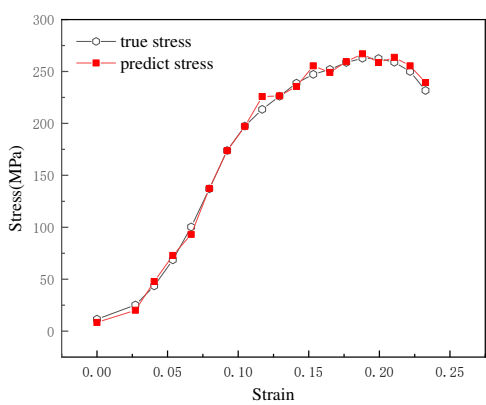

(a) at $25^{\circ} \mathrm{C}$

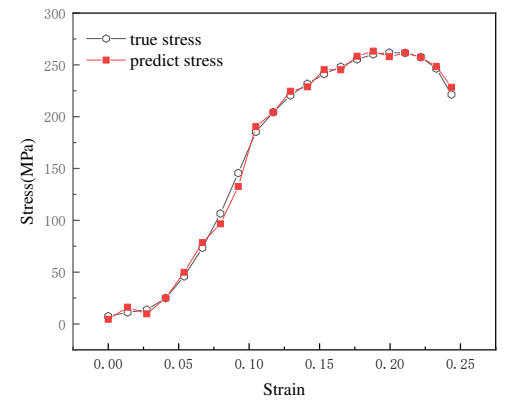

(b) at $100^{\circ} \mathrm{C}$

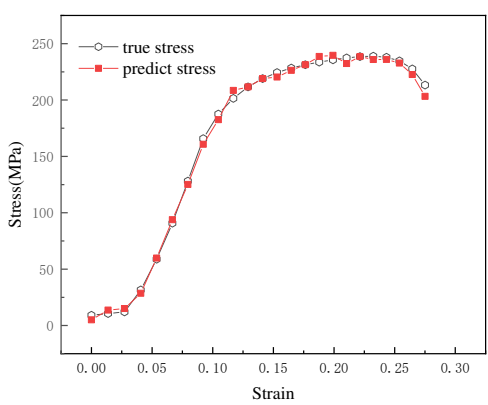

(c) at $200^{\circ} \mathrm{C}$

Fig. 9 The stress-strain contrast curve at strain rate $\dot{\varepsilon}=0.1$

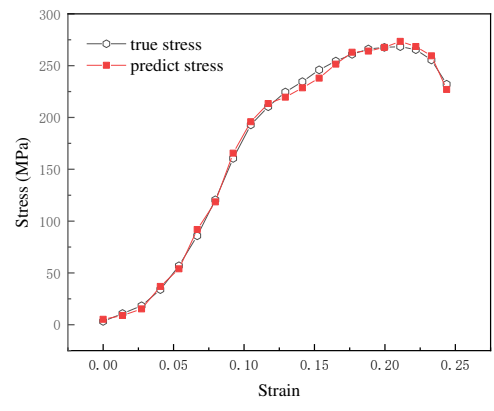

(a) at $50^{\circ} \mathrm{C}$

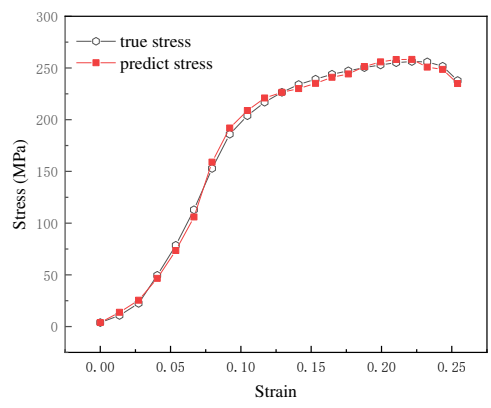

(b) at $150^{\circ} \mathrm{C}$

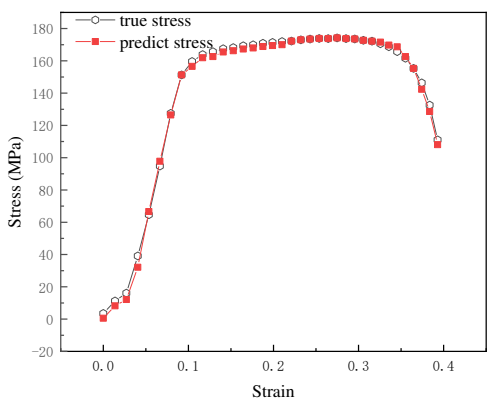

(c) at $250^{\circ} \mathrm{C}$

Fig. 10 The stress-strain comparison curve at strain rate $\dot{\varepsilon}=0.01$

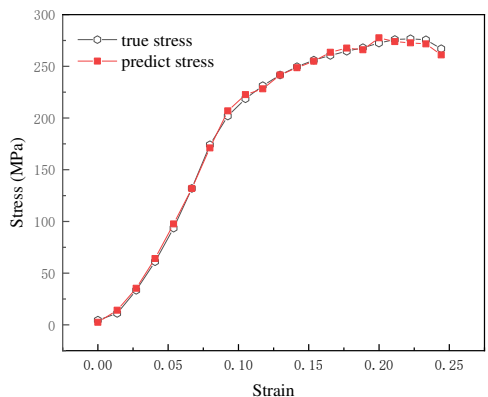

a) at $100^{\circ} \mathrm{C}$

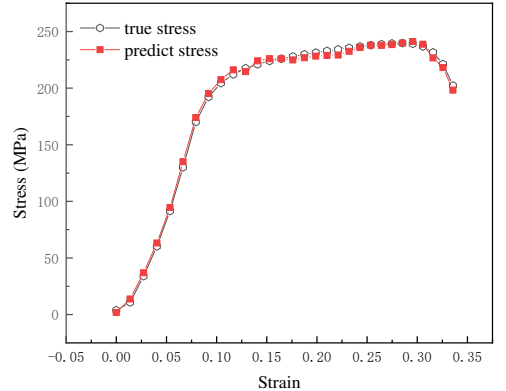

b) at $150^{\circ} \mathrm{C}$

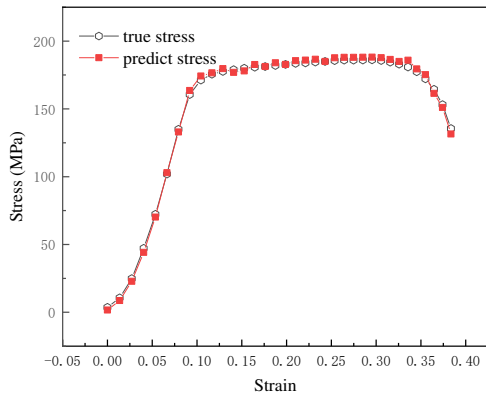

c) at $200^{\circ} \mathrm{C}$

Fig. 11 The stress-strain comparison curve at strain rate $\dot{\varepsilon}=0.001$,

As can be knows from Figures 9, 10 and 11 above, the data predicted by the BP neural network are very highly fitted with the true stress strain data, and the stress strain curve between different temperatures at the same strain rate is more and more fitted as the temperature increases. It can be seen that the BP neural network has a good effect in the prediction of the 6061T6 aluminum alloy constitutive equation, and the constitutive model can be applied in the numerical simulation to provide data that approximates the properties of the true material.

\section{The study of numerical simulation}

\subsection{The size of part and blank}

In this paper, the 6061-T6 aluminum alloy blank 
is used as the research object to analyze cylindrical cup with spherical bottom under non-isothermal hydroforming. The mechanical property of 6061-T6 aluminum alloy is shown in Table 2, and the CAD model of cylindrical cup with spherical bottom is shown in Figure 12.

Tab.2 Mechanical property of the blank of 6061-T6 aluminum alloy

\begin{tabular}{ccccc}
\hline $\begin{array}{c}\text { yield strength } \sigma_{s} \\
/ \mathrm{MPa}\end{array}$ & $\begin{array}{c}\text { tensile strength } \sigma_{b} \\
\mathrm{MPa}\end{array}$ & elastic modulus $/ \mathrm{GPa}$ & Poisson's ratio & elongation $/ \%$ \\
\hline 276 & 310 & 68.9 & 0.33 & 12 \\
\hline
\end{tabular}

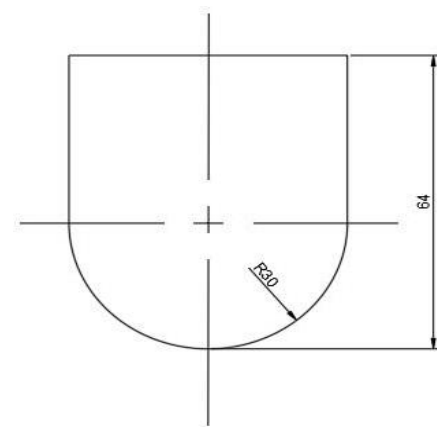

Fig. 12 CAD model of cylindrical cup with spherical bottom

The blank size is estimated by the BES blanking project of DYNAFORM software. It is concluded that the blank size is $128 \mathrm{~mm}$ in diameter. A 3D model of the mold is built in Creo software, and the detailed tool size is shown in Table 3. The models of mold and blank are imported into Abaqus to create a numerical simulation model of the cylindrical cup with spherical bottom, as shown in Figure 13. The initial coefficient of friction between the blank and the punch and die is 0.1 . The analysis process is selected: display-temperaturepower-displacement, the total duration of the analysis process is set to $0.5 \mathrm{~s}$, where in the first $0.1 \mathrm{~s}$ is the preswelling duration, the stamping stroke is $64 \mathrm{~mm}$, and the stamping speed is $10 \mathrm{~mm} / \mathrm{s}$.

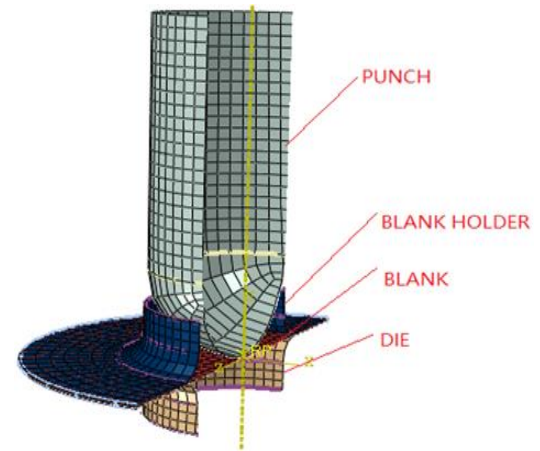

Fig.13 CAE model of cylindrical cup with spherical bottom

Tab.3 Size of molds

\begin{tabular}{cccccc}
\hline $\begin{array}{c}\text { Radius of Punch } \\
(\mathrm{mm})\end{array}$ & $\begin{array}{c}\text { Depth of } \\
\text { Punch }(\mathrm{mm})\end{array}$ & $\begin{array}{c}\text { Inner Diameter } \\
\text { of Die }(\mathrm{mm})\end{array}$ & $\begin{array}{c}\text { Depth of die } \\
(\mathrm{mm})\end{array}$ & $\begin{array}{c}\text { Length of } \\
\text { Flange }(\mathrm{mm})\end{array}$ & $\begin{array}{c}\text { Fillet Radius of Punch and Die } \\
(\mathrm{mm})\end{array}$ \\
\hline 30 & 64 & 62.2 & 70 & 10 & 5 \\
\hline
\end{tabular}

\subsection{Effect of cavity pressure curve on forming}

In order to determine the optimal cavity pressure curve, a total of 9 cavity pressure combinations, $5 \mathrm{MPa}, 10 \mathrm{MPa}, 15 \mathrm{MPa}, 20 \mathrm{MPa}, 25 \mathrm{MPa}$, $30 \mathrm{MPa}, 35 \mathrm{MPa}, 40 \mathrm{MPa}$ and $45 \mathrm{MPa}$, were simulated. and the numerical simulation cavity pressure curve was shown in Figure 14. The wall thickness distribution map after the simulation is shown in Figure 16.

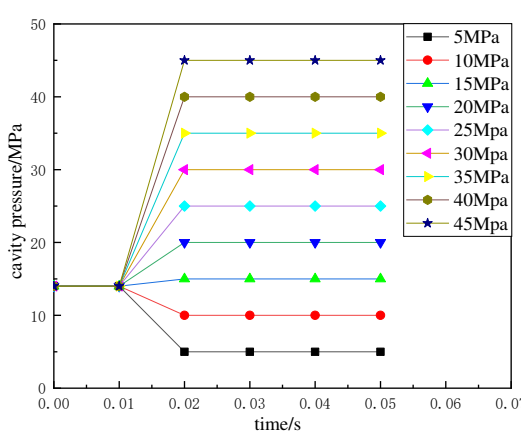

Fig. 14 Loading path of the cavity pressure
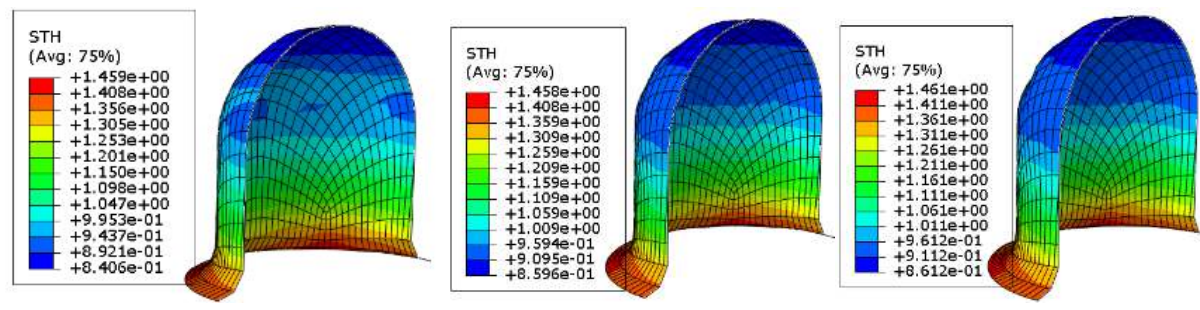

a) $=5 \mathrm{MPa}$

b) $=10 \mathrm{MPa}$

c) $=15 \mathrm{MPa}$ 


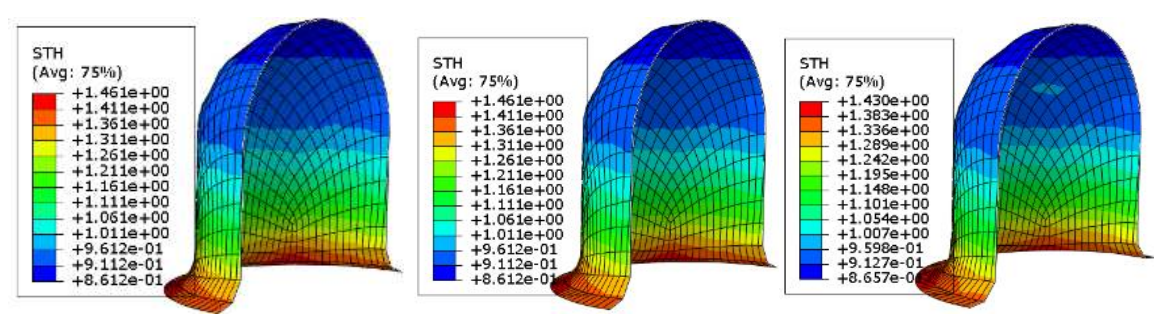

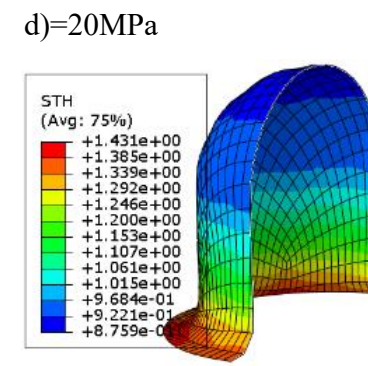

g) $=35 \mathrm{MPa}$

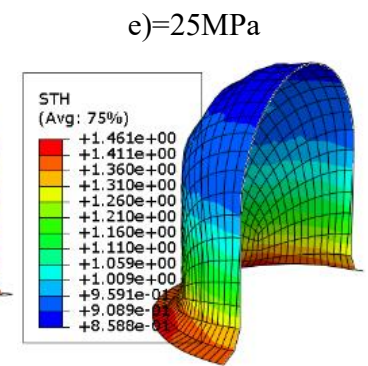

h) $=40 \mathrm{MPa}$

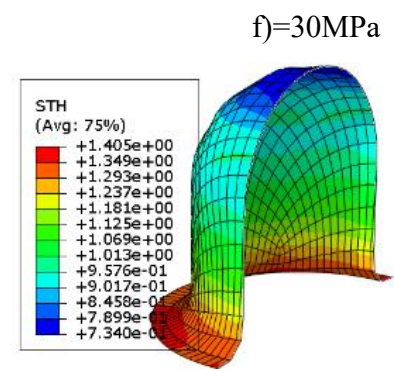

i) $=45 \mathrm{MPa}$

Fig. 15 Wall thickness distribution map after simulated forming

As shown in Figure 15, when the cavity pressure increases from $5 \mathrm{MPa}$ to $45 \mathrm{MPa}$, the thinnest part gradually diffuses from the top to the part where the ball floor is combined with the straight wall area, peaking at $35 \mathrm{MPa}$. As the pressure continues to increase, the minimum thickness of the blank gradually decreases. When the cavity pressure is increased to $45 \mathrm{MPa}$, the minimum wall thickness has been reduced to 0.734 , at which point the maximum thinning rate is greater than $25 \%$, proving that the top is nearly cracked at this time, and the part is not qualified. When the cavity pressure is less than $14 \mathrm{MPa}$, with the downstream of the punch, it is less than the pressure of the pre-expansion, it is not possible to reduce the friction between the blank and the die, the flow of the blank in the flange area can be regarded as equivalent to the effect of normal rigid mold deep. Therefore, it will lead to excessive thinning of the area where spherical bottom is combined with the straight wall area. When the cavity pressure reaches $15 \mathrm{MPa}$ to $35 \mathrm{MPa}$, the friction between the die and the blank is gradually reduced with the lubrication phenomenon of the fluid in the cavity, the flow of the blank is enhanced in the flange area, and the wall thickness of the top area of the spherical shape is evenly distributed. When the cavity pressure is $35 \mathrm{MPa}$, the blue area reaches the maximum, and the minimum wall thickness of the hemispheric part is 0.8759 parts, the overall wall thickness distribution is more uniform, and the forming effect is better. With the further increase of cavity pressure, when the it is $45 \mathrm{MPa}$, the slow flow of the blank causes the it to accumulate too much in the flange area, and the top area of the spherical shape is thinned seriously, resulting in cracking. The minimum wall thickness is distributed with the cavity pressure as shown in Figure 16.

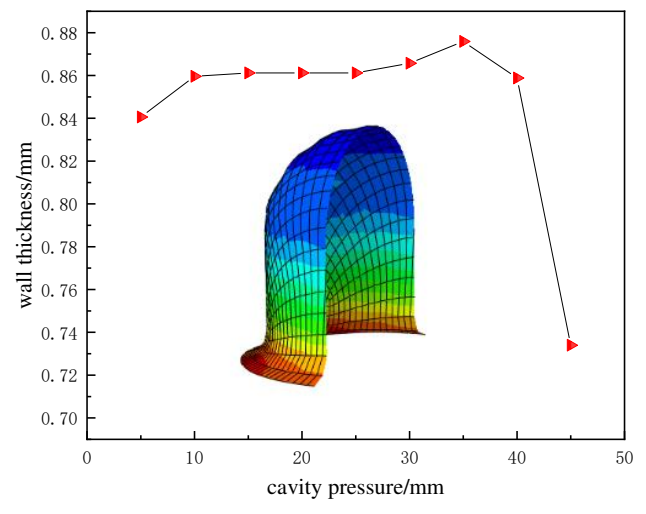

Fig. 16 Minimum wall thickness distribution

\subsection{The effect of non-isothermal on forming}

The numerical simulation of non-isothermal hydroforming needs to build the non-isothermal environment. This paper is simulated in the Abaqus software, applying a separate temperature to the punch, and another separate temperature to the die, blank and blank holder, and to achieve the non-isotherms by controlling the difference between the two temperatures.

\subsubsection{The scheme of non-isothermal simulation}

When the 6061-T6 aluminum alloy cylindrical cup with spherical bottom part is non-isothermal hydroforming, it is very important to control the temperature of each area of the blank. In order to facilitate the experimental operation, this paper 
simulates the application of non-isotherms to punch and die. The temperature of the die is used below to refer to the temperature of the die, blank, and blank holder. In order to systematically study the effect of non-isotherms of punch and die on the deep drawing, the simulation scheme is shown in Table 4.

Tab.4 Simulation scheme of punch and die temperature combination

\begin{tabular}{ccc}
\hline Combination & Punch Temperature $/{ }^{\circ} \mathrm{C}$ & Die Temperature $/{ }^{\circ} \mathrm{C}$ \\
\hline 1 & 25 & 150 \\
\hline 2 & 50 & 150 \\
\hline 3 & 100 & 150 \\
\hline 4 & 150 & 150 \\
\hline 5 & 25 & 200 \\
\hline 6 & 50 & 200 \\
\hline 7 & 100 & 200 \\
\hline 8 & 150 & 200 \\
\hline 9 & 25 & 250 \\
\hline 10 & 50 & 250 \\
\hline 11 & 100 & 250 \\
\hline 12 & 150 & 250 \\
\hline
\end{tabular}

4.3.2 The effect of non-isothermal hydroforming of on equivalent plastic strain

The plastic changes caused by the temperature increase during the forming of the blank are evaluated by Plastic Equivalent Strain (PEEQ). The PEEQ is the index of accumulative plastic strain in the deep drawing of the blank. And the PEEQ distribution map derived from the numerical simulation of non-isothermal hydroforming is shown in Figure 17.

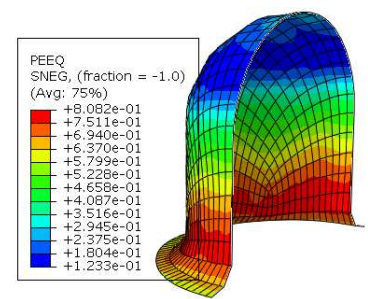

Combination 1

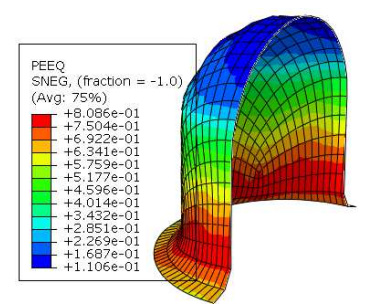

Combination 4

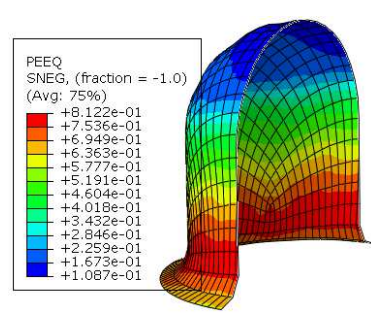

Combination 7

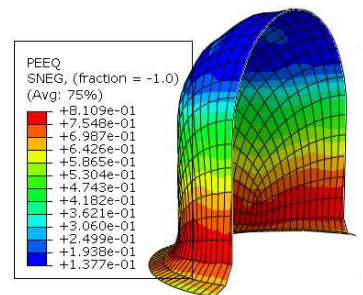

Combination 2

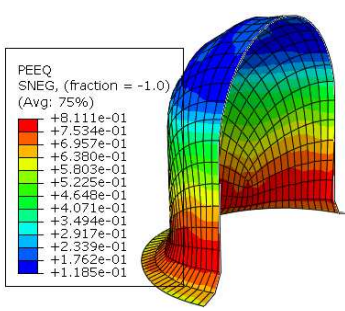

Combination 5

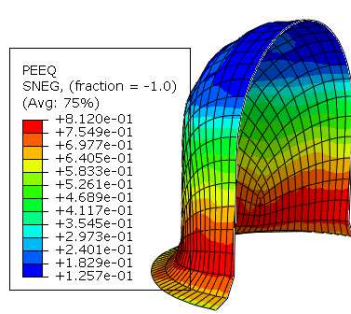

Combination 8

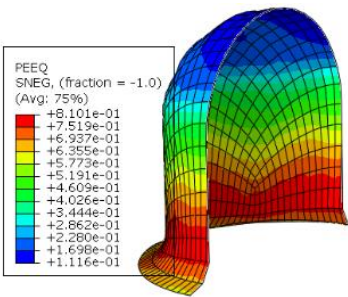

Combination 3

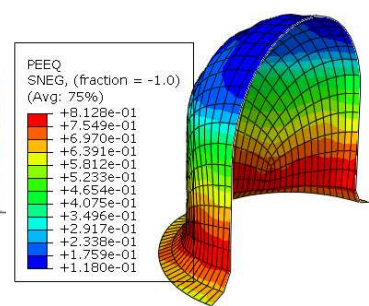

Combination 6

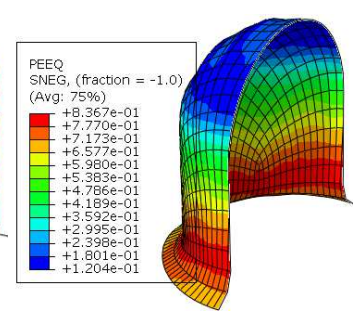

Combination 9 


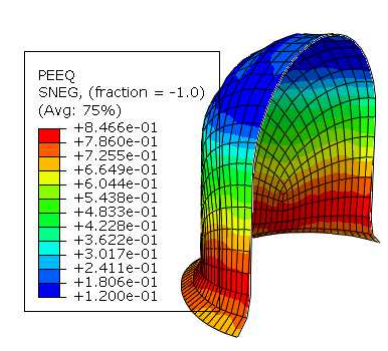

Combination 10

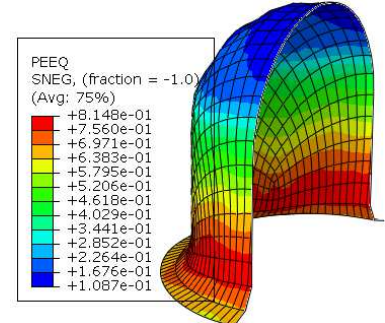

Combination 11

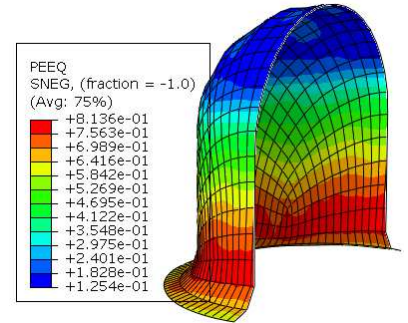

Combination 12

Fig. 17 Equivalent plastic strain distribution map

Combination 1 to 12 in Figure 17 corresponds to the non-isothermal simulation scheme in Table 4, at the beginning of the deep drawing process, the deformation of the flange region is mainly elastic deformation, and the part contacts with the punch begins to plastic deformation, and as the punch continues to deform to the full forming stage, the deformation is mainly plastic deformation. It can be seen from the numerical distribution of medium-effect plastic strain in the figure that the plastic strain is greatest in the flange area. The blank is compressed and deformed from the flange into the die, so the plastic strain in the flange area is greatest. The minimum plastic strain occurs at the bottom of the ball, when the punch comes into contact with the blank, the area where the punch comes into contact with the blank is thinned and the plastic strain is small.

The plastic equivalent strain is in transition at the area that the straight wall area in contact with the bottom of the ball, and the equivalent plastic strain value is more balanced. The punch has the same temperature in same column in Figure 17, and the die has the same temperature in the same row. Equivalent plastic strain increases as the temperature of the die increases in order in each column, and the trend occurs in each row that first increase and then decrease, with the maximum equivalent plastic strain appearing in $50^{\circ} \mathrm{Cof}$ punch in each row. The maximum point of equivalent plastic strain value appears in combination 6 , its value is 8.466 , and the minimum value of equivalent plastic strain is small. The conclusion of the uniaxial tensile test is verified, and the softening effect of 6061-T6 aluminum alloy is best when the temperature of die is $50^{\circ} \mathrm{Cand}$ the plasticity reaches the maximum in the combination.

\subsubsection{The effect of non-isothermal hydroforming on thickness distribution}

This section evaluates the effect of temperature changes on part thickness during the non-isothermal hydroforming by the thickness distribution of the cylindrical cup with spherical bottom. According to the simulation scheme shown in Table 5, there are 12 combinations of non-isotherms. In the ABAQUS software, the numerical simulation of non-isothermal hydroforming is carried out, and the thickness distribution of the cylindrical cup with spherical bottom base is shown in Figure 18.

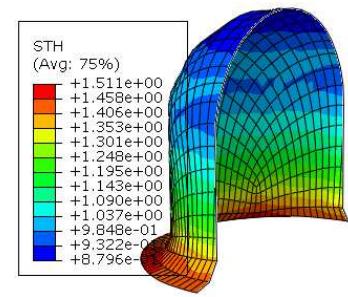

Combination 1

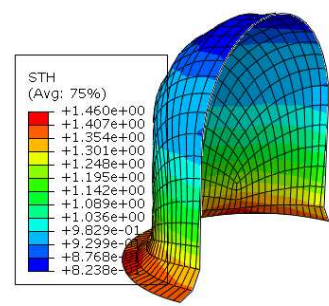

Combination 4

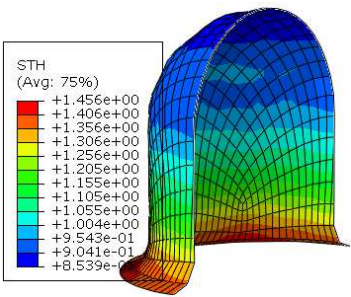

Combination 2

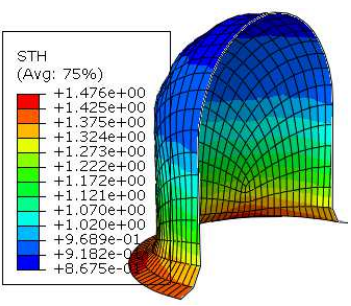

Combination 5

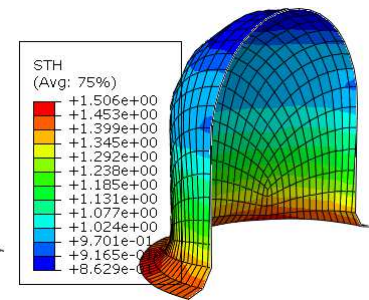

Combination 3

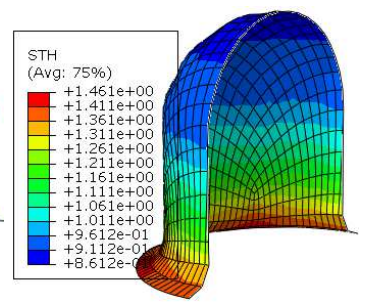

Combination 6 

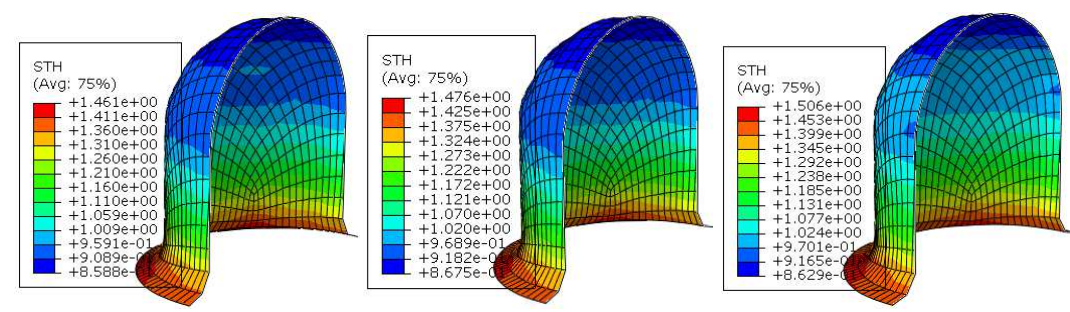

Combination 7

Combination 8

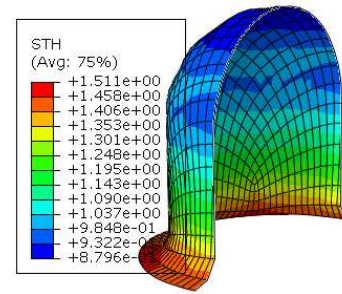

Combination 10

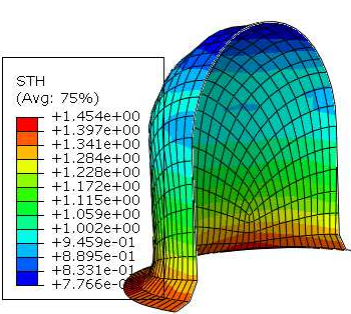

Combination 11
Combination 9

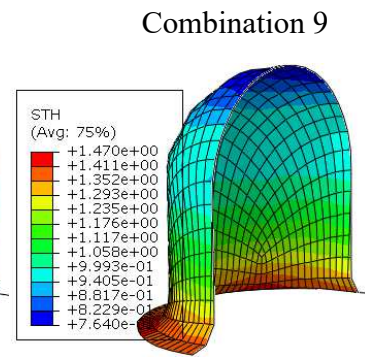

Combination 12

Fig.18 Wall thickness distribution map

As shown in Figure 18, the punch has the same temperature in each column, and the die, blank, and blank holder have the same temperature in each row. The areas with the greatest thinning rate are mainly concentrated in the bottom and the transition area of the bottom to the straight wall, and thickening appears at the flange and the transition area that the flange to the straight wall. The part with a thinning rate of 0 occurs in the middle position of the straight wall. Due to the flange area can be removed the later, the thickening value of the transition area from the straight wall to the flange is used as the thickening analysis. The maximum, minimum and difference of the wall thickness are shown in Table 5.

Tab.5 The maximum, minimum and difference of the wall thickness

\begin{tabular}{cccc}
\hline Combination & maximum $(\mathrm{mm})$ & minimum $(\mathrm{mm})$ & difference $(\mathrm{mm})$ \\
\hline 1 & 1.511 & 0.8796 & 0.6314 \\
\hline 2 & 1.456 & 0.8539 & 0.6021 \\
\hline 3 & 1.506 & 0.8629 & 0.6431 \\
\hline 4 & 1.460 & 0.8233 & 0.6367 \\
\hline 5 & 1.476 & 0.8675 & 0.6085 \\
\hline 6 & 1.461 & 0.8612 & 0.5998 \\
\hline 7 & 1.461 & 0.8588 & 0.6022 \\
\hline 8 & 1.476 & 0.8675 & 0.6085 \\
\hline 9 & 1.506 & 0.8629 & 0.6448 \\
\hline 10 & 1.511 & 0.8776 & 0.6034 \\
\hline 11 & 1.454 & 0.7766 & 0.6774 \\
\hline 12 & 1.470 & 0.7640 & 0.706 \\
\hline
\end{tabular}

As can be known from the data in Table 5, when the punch temperature is $25^{\circ} \mathrm{C}$ (Combination 1,5 and 9 in Table 4), the minimum thickness of the blank decreases gradually as the die temperature increases. This is because the blank has a higher temperature relative to the punch, the temperature difference is large between blank and punch. During contact, the temperature drops too fast, resulting in the "shock chilling" effect, similar to quenching in heat-treating.
Due to extreme cooling the pull strength increases but the plasticity decreases, the area of punch fillet is thinned excessively, and the difference between thinning rate is larger and the molding effect is poor. Although a lower temperature of punch is required for the thinning rate of the part, it is not appropriate to use a low temperature of punch for the uniformity of the wall thickness distribution.

The data in the table5 show that the wall thickness 
difference of the blank is large when the temperature of punch is greater than or equal to 100 degrees $\mathrm{C}(3,4,7$, 8,11 and 12 of table 5), which proves that the blank uniformity is poor. This is because the temperature difference is too small between the punch and the blank, which causes the blank to cool down slowly, the increase rate of plasticity is much higher than the rate of decrease in tensile strength. In particular, the difference is maximum in wall thickness distribution when the punch is greater than 100 degrees $\mathrm{C}$, such as combination 11 and 12 , the maximum wall thickness is 1.454 in combination 11, and 1.470 in combination 12 . The value is not very large in terms of the maximum wall thickness alone, this is because the blank temperature is $200^{\circ} \mathrm{C}$ and $250^{\circ} \mathrm{Cat}$ the beginning of drawing, and 6061-T6 aluminum alloy began to appear softening behavior at $200^{\circ} \mathrm{C}$, blank fluidity increased but the maximum thickness of the flange area becomes smaller. The minimum thicknesses of combination 11 and 12 are 0.7766 and 0.7640 , respectively. As can be seen from the combination 16 , the minimum wall thickness is distributed at the transition area from the bottom to the straight wall area, this area is excessively thinned due to a significant decrease in tensile strength, and the minimum wall thickness value is 0.7640 in the combination 12, which has reached the edge of rupture. Therefore, in order to improve the part quality, the temperature difference should be smaller between the punch and the blank, and the punch temperature must not be greater than $100^{\circ} \mathrm{C}$.

In the wall thickness cloud map of the punch temperature from $25^{\circ} \mathrm{C}$ to $100^{\circ} \mathrm{C}$, it is found that the minimum wall thickness increases and then decreases, when the punch temperature is $50^{\circ} \mathrm{C}$, the wall thickness difference is minimal, so the optimal temperature of the punch is $50^{\circ} \mathrm{C}$. Observe the die temperature change when the punch temperature is $50^{\circ} \mathrm{C}$ (combination 2, 6 and 10 in Table 5), The wall thickness difference is larger in combination 2, mainly because the blank temperature is low, and the plasticity has not been significantly improved. Therefore, there is not much different between this result and the environment in which the non-isothermal is not applied. The maximum thickness is 1.461 in the combination 6 , at which point the blank has reached $200^{\circ} \mathrm{C}$, and the softening behavior has begun to appear of 6061-T6 aluminum alloy, as can be seen from the wall thickness distribution cloud map of Figure 16, the difference is minimal when the minimum wall thickness value is 0.8612 . In combination 10 , the rate of blank plasticity increase and tensile strength decrease do not match, resulting in uneven wall thickness distribution and large difference.

In this section, the numerical simulation forming effect of non-isothermal hydroforming is analyzed from the maximum wall thickness value, minimum wall thickness value and wall thickness difference. The analysis leads to the following conclusions: the temperature difference between die and punch should be as large as possible, in this way, the plasticity of the blank to be reduced and the tensile strength to be enhanced, because of the heat exchange generated by the contact between the blank and the punch. However, the punch temperature cannot be too low, the optimal temperature is $50^{\circ} \mathrm{C}$, and the temperature of the blank cannot be selected too high, When the temperature is greater than $250^{\circ} \mathrm{C}$, the rate of tensile strength decreases far beyond the increase rate of plasticity, and the transition area is excessively thinned or even cracked between the part ball bottom and straight wall. Therefore the optimal temperature of blank, blank holder and die is $200^{\circ} \mathrm{C}$.

\section{Experimental verification}

The blank material is 6061-T6 aluminum alloy rolled blank, the thickness is $1 \mathrm{~mm}$, and the blank radius is $128 \mathrm{~mm}$. Place a plastic film between the plate and the die to protect the surface of the die.

The cavity pressure is $35 \mathrm{MPa}$, the blank holder gap is selected at $1.1 \mathrm{~mm}$, the punch temperature is $50^{\circ} \mathrm{C}$, the temperature of die, blank and blank holder is $200^{\circ} \mathrm{C}$, the speed of deep drawing is $10 \mathrm{~mm} / \mathrm{s}$ and the depth is $64 \mathrm{~mm}$.

The experimentally obtained parts are shown in Figure 19, where 19a is the ordinary hydrodynamic deep drawing, $19 \mathrm{~b}$ is the non-isothermal hydroforming, using the MT500 ultrasonic thickness gauge shown in Figure 20, the wall thickness value is measured from bottom to top along test point shown in Figure 19. Each part is measured 70 times and the measurement data is fitted in the origin software. The fitted wall thickness 
distribution is shown in Figure 21.

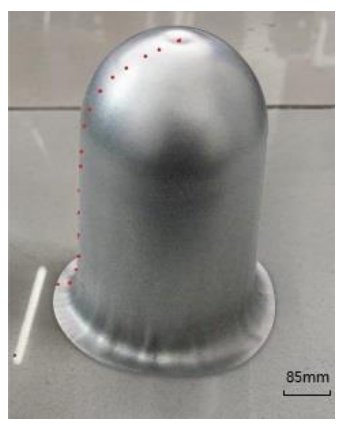

a)

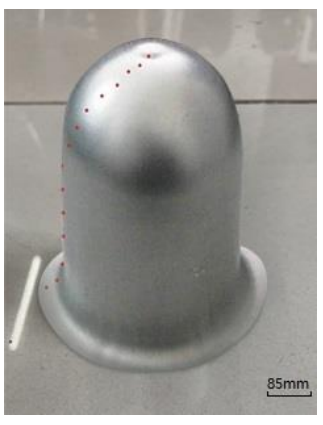

b)
Fig.19 cylindrical cup with spherical bottom drawing

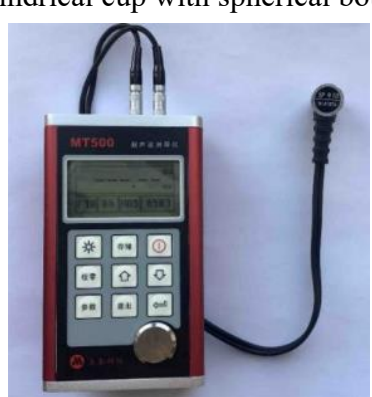

Fig.20 MT500 Ultrasonic Thickness Gauge

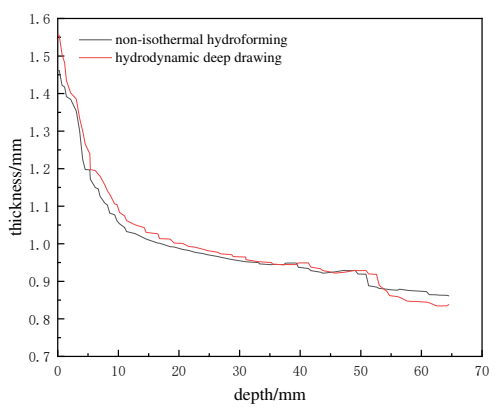

Fig. 21 Wall thickness distribution map

The wall thickness distribution is shown in Figure 19, with the same process parameters but different temperature conditions, room temperature and nonisotherms. From Figure 19a, it can be seen that the blank appeared wrinkles in the flange area, because of the low plasticity at room temperature, the accumulation caused by the difficulty of the flow of blank. In Figure 19b, the plasticity of the blank material is improved at non-isotherms, so there is no wrinkle in the flange area. By measuring the thickness of the test point, the wall thickness distribution obtained after fitting is shown in Figure 21. It can be found from the figure that blank thickness uniformity is better under the non-isothermal hydroforming, the difference is small between the maximum and minimum values of the wall thickness, but the difference is larger at room temperature. The distribution of wall thickness obtained by the experiment is more consistent with the law obtained by numerical simulation, and the minimum value of wall thickness appears in the bottom area, while the wall thickness is relatively flat in the transition area between the bottom and the straight wall.

\section{Conclusion}

In this paper, 6061-T6 aluminum alloy cylindrical cup with spherical bottom is as the research object, the temperature forming performance of 6061-T6 aluminum alloy is studied by uniaxial tensile test, and the thermoforming constitutive model is constructed based on BP artificial neural network. This model is used to simulate the process of the non-isothermal hydroforming in the ABAQUS software to arrive at the optimal combination of parameters. The conclusions obtained are as follows:

1. Comparing the BP neural network model prediction with the true stress-strain curve from the data converted from the uniaxial tensile test, the fit is $\mathrm{R}=0.9991$ between the data predicted by the neural network and the true stress-strain data, and the accuracy reaches the required 0.001 . At the same strain rate, the fit is getting higher and higher as the temperature increases. It can be seen that the BP neural network has a good effect in the prediction of the 6061-T6 aluminum alloy structure equation, and the model can be applied to the numerical simulation to provide data that is closer to the properties of the real material.

2. With the downstream of the punch, due to the low cavity pressure, it is not possible to reduce friction through overflow, which can lead to excessive thinning of the straight wall area near the flange. With the further increase of cavity pressure, the slow flow of blank causes it to accumulate too much in the flange area, the top area of the spherical shape is thinned seriously, resulting in cracking. The part is better formed when the pressure of the chamber is $35 \mathrm{MPa}$.

3. The blank temperature is lower at the bottom of the punch, the material strength is higher, and the temperature at the corner of the die is high, and the softening effect is obvious but the intensity is low of the flowing blank. The optimal difference temperature is set to $50{ }^{\circ} \mathrm{C}$ for the punch, and $200^{\circ} \mathrm{C}$ for the die, 
blank holder and blank, at which point the equivalent plastic strain and thickness are evenly distributed.

4. Using the data of the best cavity pressure curve and optimal temperature combination, the results show that the wall thickness distribution of the experimental part is more consistent with the numerical simulation, the hydroforming difference temperature drawing improves the plasticity of the plate material, and the wall thickness distribution of the experimental part is more uniform.

\section{Ethics declarations}

\section{Ethical Approval}

Not applicable

\section{Consent to Participate}

Not applicable

\section{Consent to Publish}

Not applicable

\section{Authors Coutributions}

Xue Feng Ma: Conceptualization, Methodology, Writing- Original draft preparation, Experimental scheme design. Xiao Jing Liu: Writing- Reviewing and Editing. Li Chao: Experiment. Jin Qin: Verification. Validation. Peng Chen: Supervision.

\section{Funding information}

This paper was financially Supported by Harbin academic leader fund (2017RAXXJ008) and National natural science foundation of China (51975167).

\section{Competing Interests}

Not applicable

\section{Availability of data and materials}

The data obtained in the framework of this study are available to the journal upon request.

\section{Reference}

1 Hui Li, Zhaohui Yan, Lingyong Cao (2018) Bake hardening behavior and precipitation kinetic of a novel Al-Mg-Si-Cu aluminum alloy for lightweight automotive body. Materials Science and Engineering728:88-94

2 Tisza, Miklos, Czinege, Imre (2018) Comparative study of the application of steels and aluminium in lightweight production of automotive parts. International Journal of Lightweight Materials and Manufacture1(4):229-238

3 Xiaojing LIU, Yongchao XU, Shijian YUAN(2008) Effects of Loading Paths on Hydrodynamic Deep Drawing with Independent Radial Hydraulic Pressure of Aluminum Alloy Based on Numerical Simulation. J Mater Sci Technol24(03),395-399

4 JALIL, Alireza, HOSEINPOUR GOLLO, Mohammad, SHEIKHI, M. Morad, SEYEDKASHI, S.M. Hossein (2016). Hydrodynamic deep drawing of double layered conical cups. Transactions of Nonferrous Metals Society of China26(1):237-247

5 Huiting Wang, Xiaohui Shen(2021) A novel hydrodynamic deep drawing utilizing a combined floating and static die cavity. Int $\mathrm{J}$ Adv Manuf Technol 3.

6 P.J Bolt, N.A.P.M Lamboo, P.J.C.M Rozier(2001) Feasibility of warm drawing of aluminum products . Journal of Material Processing Technology115(1):118-121.

7 LV Haiyong, SHAO Dongqiang(2020)Application of Lightweight Materials and forming Technology in Automobile Body. Modern Manufacturing Technology and Equipment (05):92-96

8 Gong Pihao, Chen Jieshi, Yang Lei(2019)Research on warm forming for AA5182 aluminum alloy used in automobile. Forging \& Stamping Technology44(05):136-141

9 Xiao Jing Liu, Hong Ying Cao, Chao Li, Jin Qin, Ji Cheng Gao(2020)Construction of 6061-T6 aluminum alloy constitutive model based on hot 
bulging test and study on the non-isothermal hydroforming process. Int J Adv Manuf Technol1 09:1625-1641.

10 Xiao Jing Liu, Ji Chen Gao, Chao Li, Hong Fu Ding(2020)Investigation on precision warm hydroforming with independent circumferential pressure of high-performance aluminum alloy parts with special-shaped bottom. Int J Adv Manuf Technol 109: 201-213

11 Serkan Toros, Fahrettin Qzturk, Ilyas Kacar(2008)Review of warm forming of aluminum-magnesium alloys. Journal of Materials Processing Technology207(1-3): 1-12

12 Jiang Yun Peng, Yue Zhu Feng, Han Xiao Ping(2003) Determination of the materials stress and strain relationship from the tensile smooth and notched bars. Journal of Mechanical Strength02:151-153+158

13 Muammer Koç, Sasawat Mahabunphachai, Eren Billur (2011) Forming characteristics of austenitic stainless steel sheet alloys under warm hydrodynamic conditions. Int $\mathrm{J}$ Adv Manuf Technol 56: 97-113

14 Gerrit Kurz(2016) Heated hydro-mechanical deep drawing of magnesium sheet metal. Essential Readings in Magnesium Technology:389-393

15 Sun-Chong Wang(2003) Artificial neural network. Interdisciplinary computing in java programming743:81-100

16 David E.Rumelhart, Geoffrey E.Hinton, Ronald J.Williams(1986) Learning representations by back-propagating errors. Nature323: 533-536

17 Han Mao Sheng, Tao Huan(2016) High temperature flow stress behavior of B10 copper alloy and BP neural network constitutive model. China Metalforming Equipment \& Manufacturing Technology51(06):112-115

This article is completed under my independent research, and without the phenomenon that quotes largely or plagiarizes other articles and so on. Therefore, I will be corresponding responsible for the thing. 


\section{Figures}

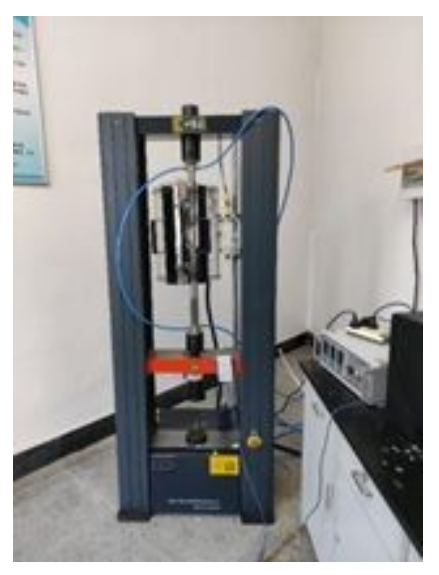

\section{Figure 1}

MTS universal electronic testing machine

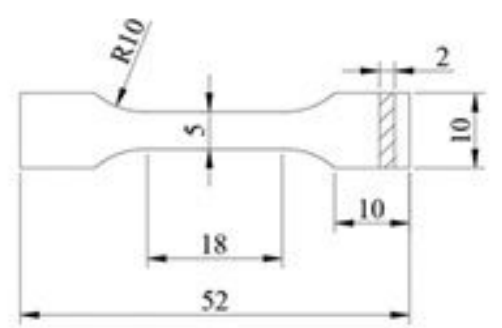

Figure 2

scale of tensile specimen

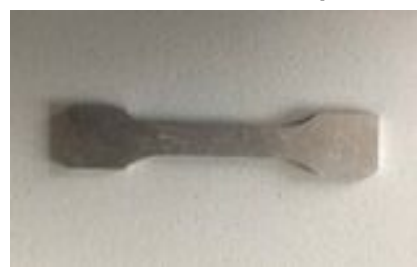

Figure 3

The tensile specimen The results of the tensile of 6061-T6 with a strain rate of $0.1 \mathrm{~s}-1$ at different

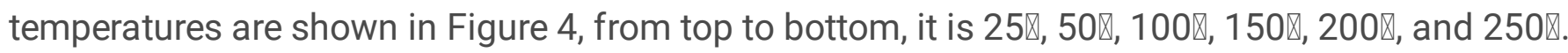

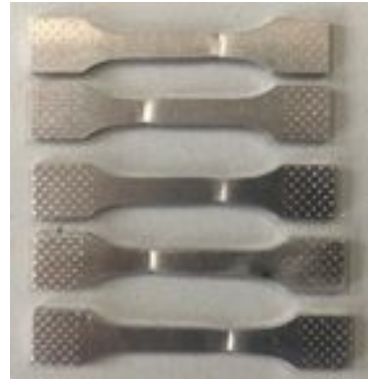


Figure 4

Specimen with a strain rate of $0.1 \mathrm{~s}-1$ at different temperatures (The temperature is $25,50,100,150,200$, and 250 from top to bottom)

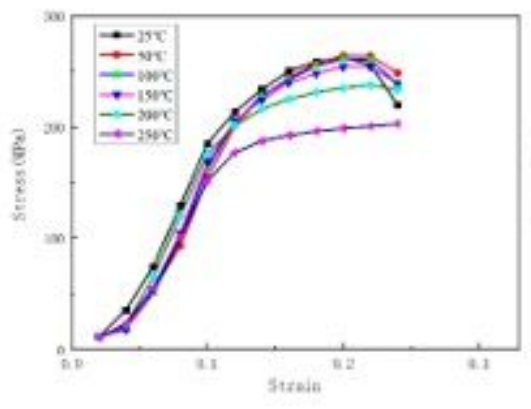

(a) $\dot{\varepsilon}=10^{-1}$

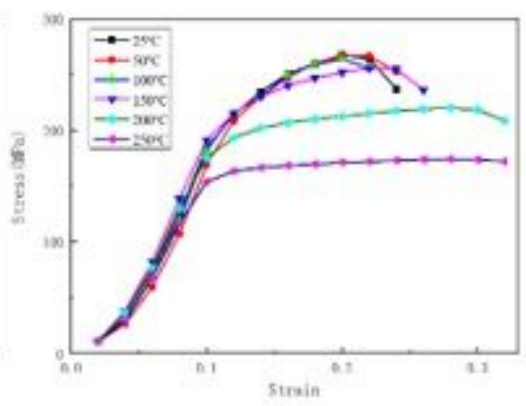

(b) $\dot{\varepsilon}=10^{-2}$

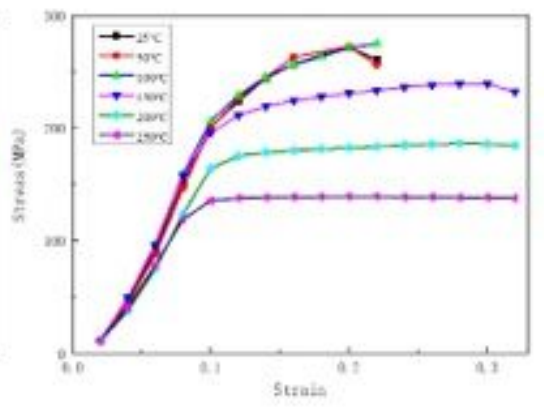

(c) $\dot{\varepsilon}=10^{-3}$

Figure 5

The true stress-strain curve at different strain rates

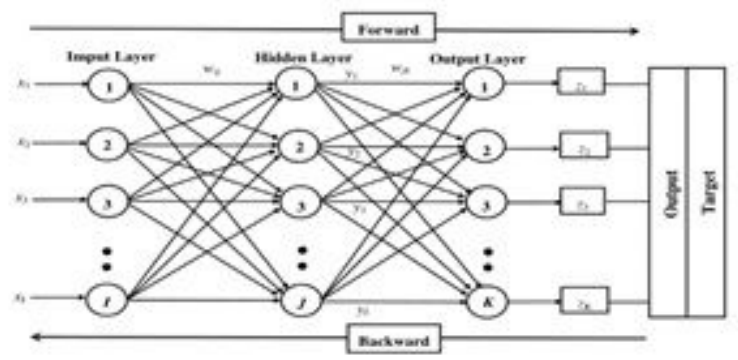

Figure 6

the structure of neural network

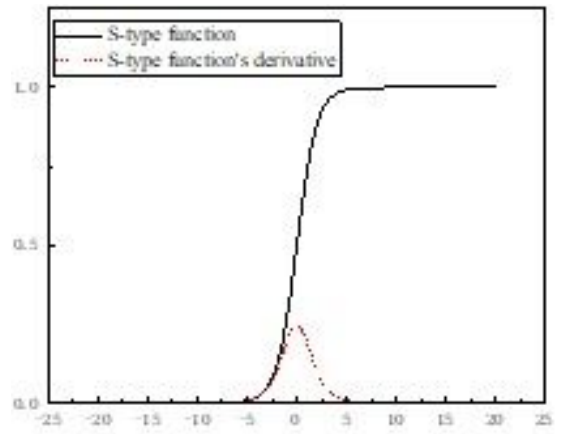

Figure 7

S-type function and its derivative curve 


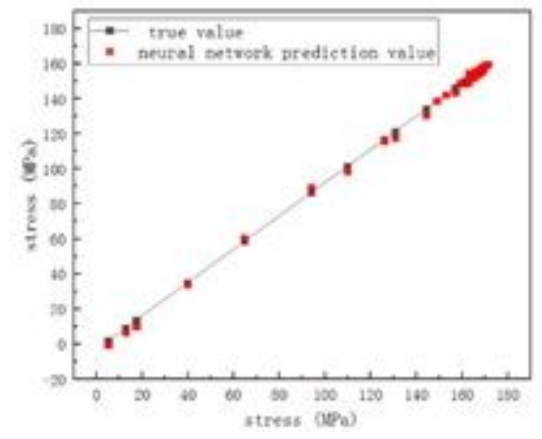

Figure 8

Correlation curve

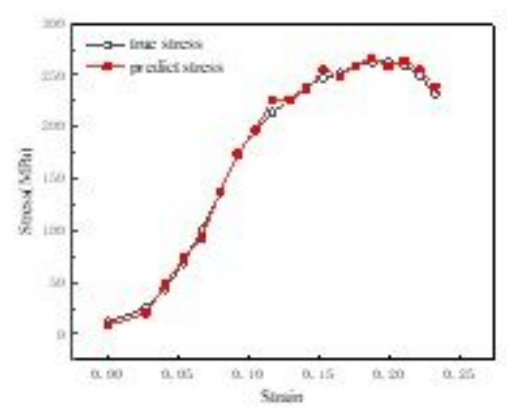

(a) at $25^{\circ} \mathrm{C}$

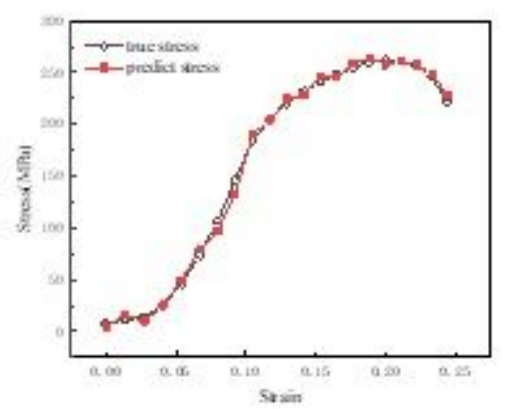

(b) at $100^{\circ} \mathrm{C}$

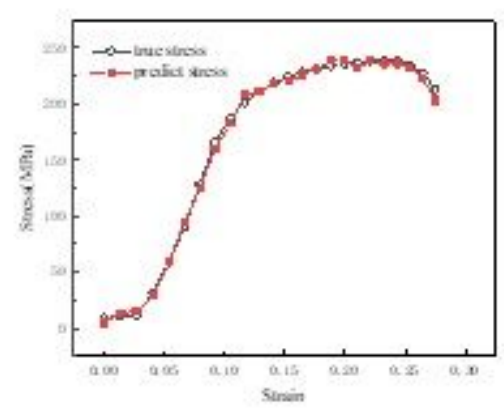

(c) at $200^{\circ} \mathrm{C}$

Figure 9

The stress-strain contrast curve at strain rate $\mathbb{Q} \mathrm{Q}=0.1$

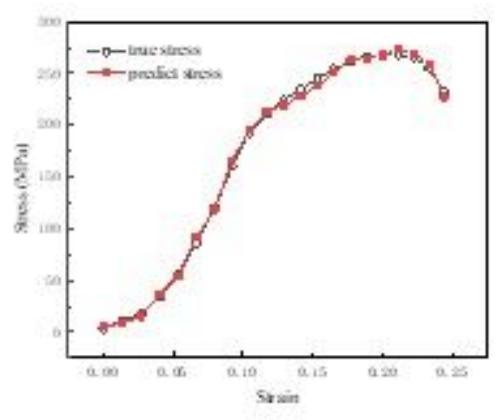

(a) at $50^{\circ} \mathrm{C}$

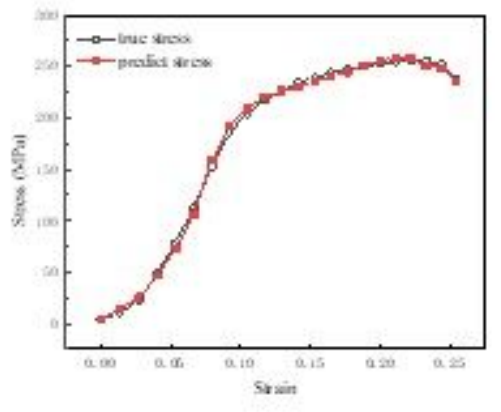

(b) at $150^{\circ} \mathrm{C}$

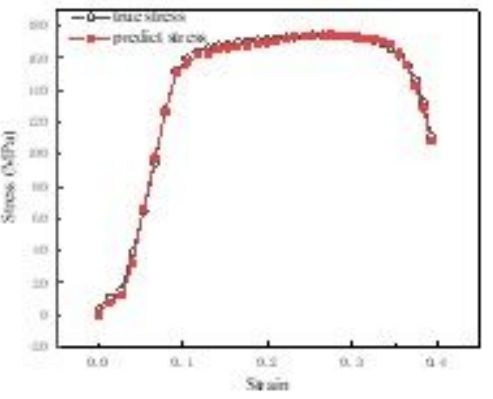

(c) at $250^{\circ} \mathrm{C}$

Figure 10

The stress-strain comparison curve at strain rate $\mathbb{Q} \mathrm{Q}=0.01$ 


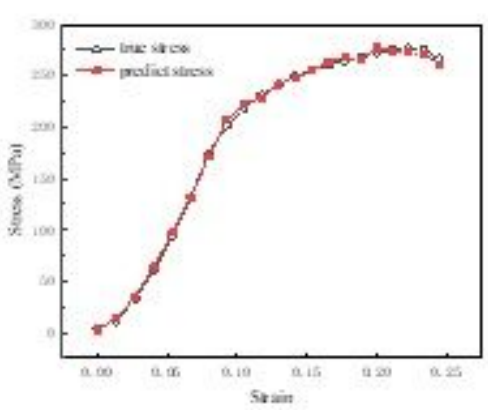

a) at $100^{\circ} \mathrm{C}$

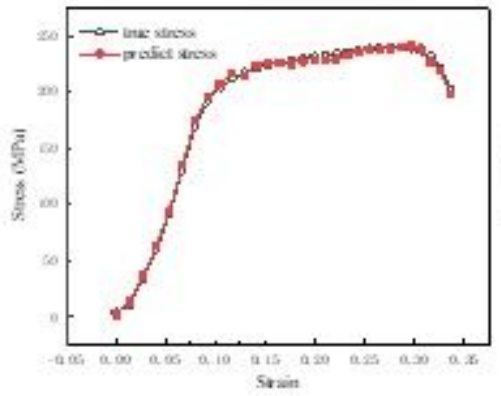

b) at $150^{\circ} \mathrm{C}$

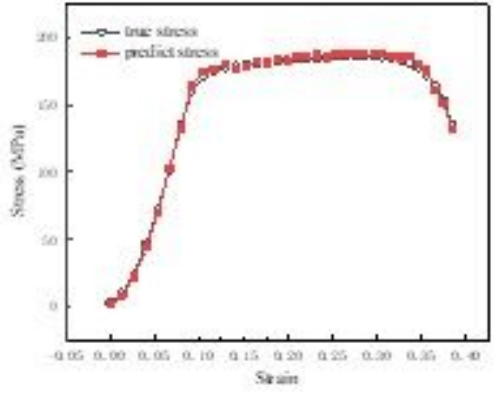

c) at $200^{\circ} \mathrm{C}$

\section{Figure 11}

The stress-strain comparison curve at strain rate $\mathbb{Q}=0.001$,

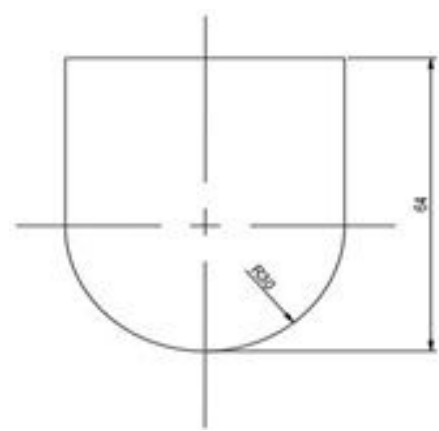

Figure 12

CAD model of cylindrical cup with spherical bottom

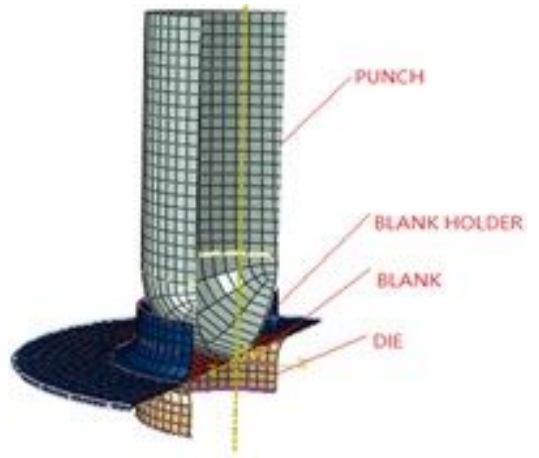

Figure 13

CAE model of cylindrical cup with spherical bottom 


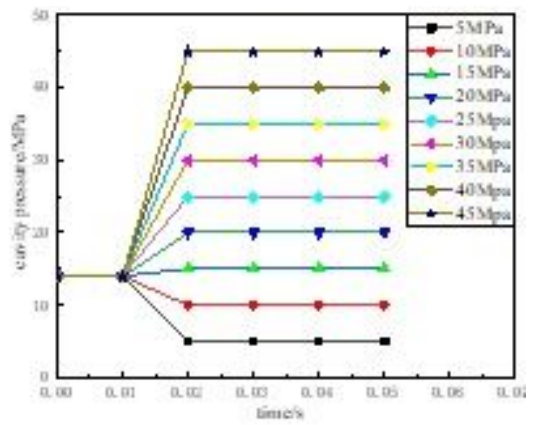

Figure 14

Loading path of the cavity pressure
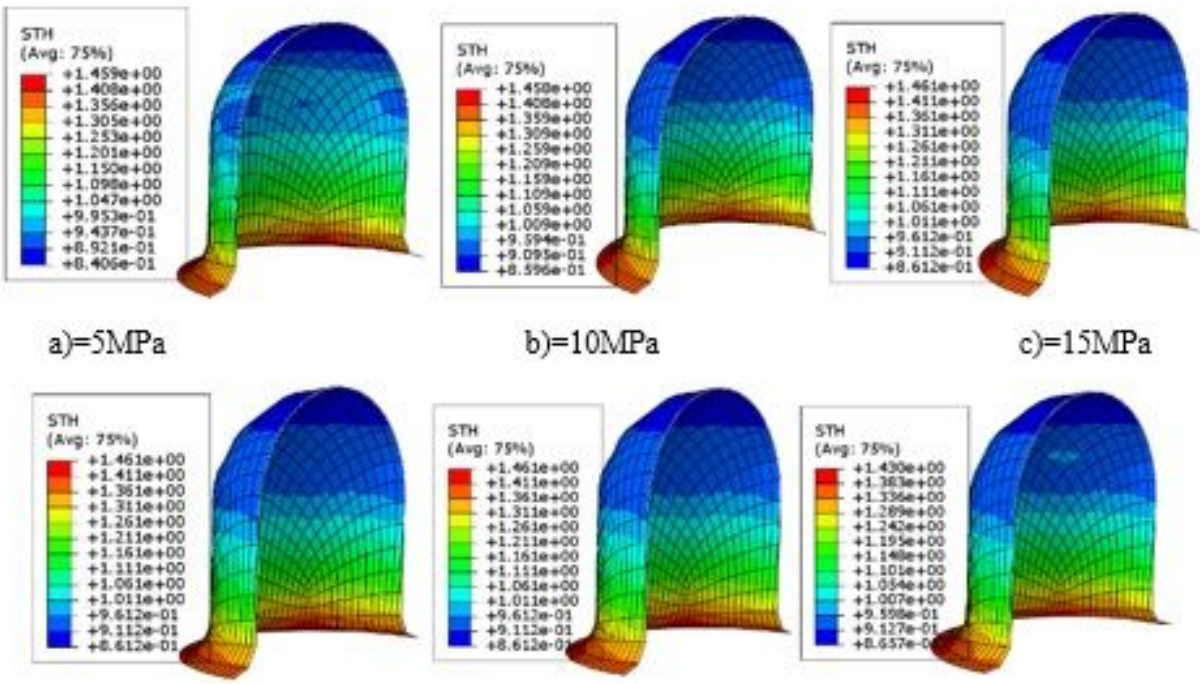

b) $=10 \mathrm{MPa}$

c) $=15 \mathrm{MPa}$

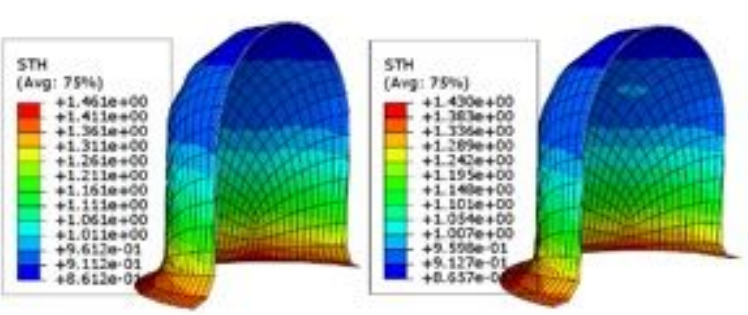

d) $=20 \mathrm{MPa}$

e) $=25 \mathrm{MPa}$

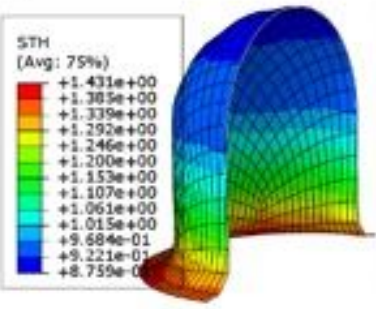

$\mathrm{g})=35 \mathrm{MPa}$

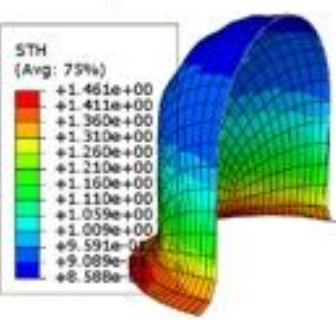

h) $=40 \mathrm{MPa}$ f) $=30 \mathrm{MPa}$

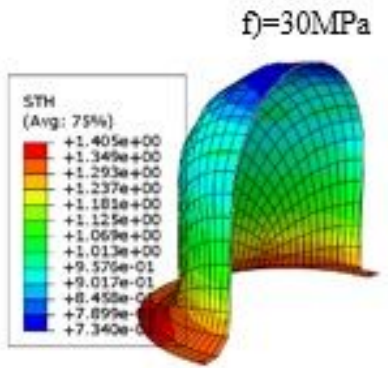

i) $=45 \mathrm{MPa}$

Figure 15

Wall thickness distribution map after simulated forming 


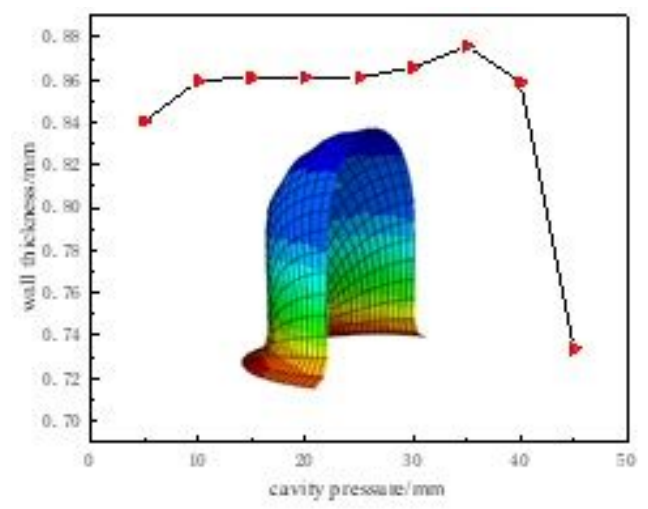

Figure 16

Minimum wall thickness distribution
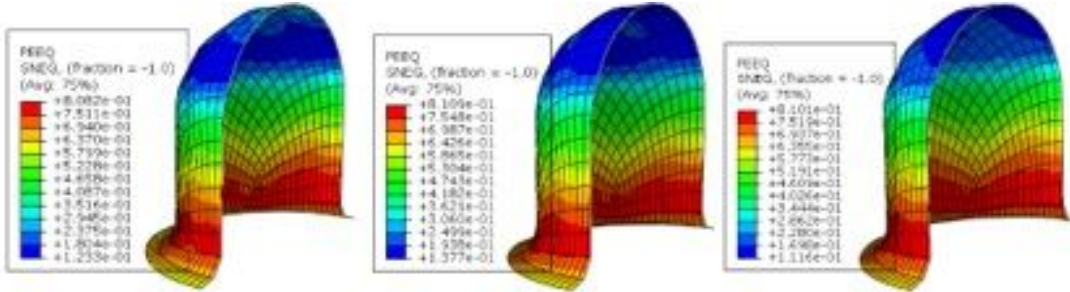

Combination 1

Combination 2

Combination 3
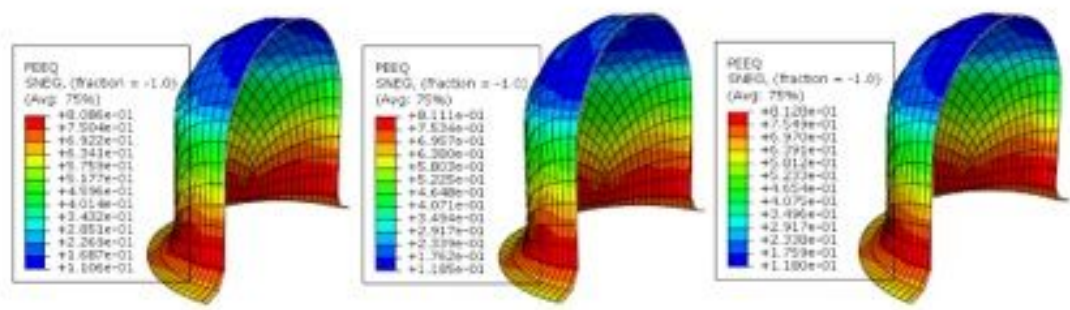

Combination 4

Combination 5

Combination 6
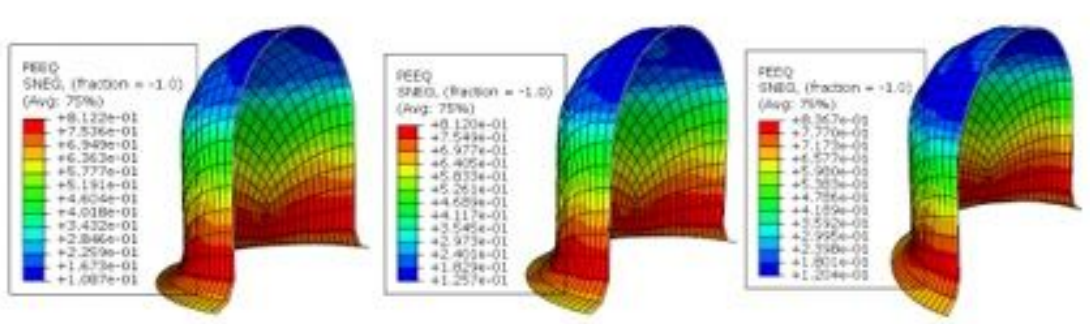

Combination ?

Combination 8

Combination 9

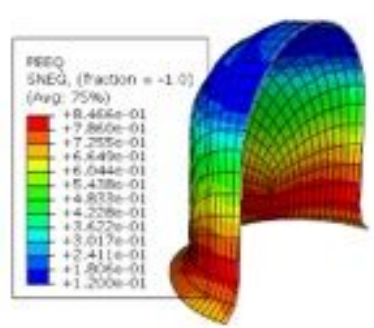

Combination 10

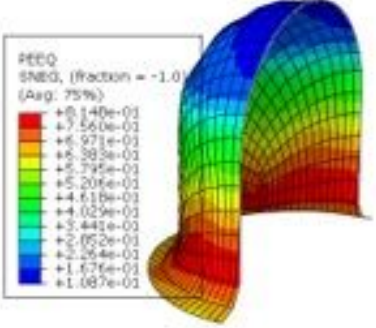

Combination 11

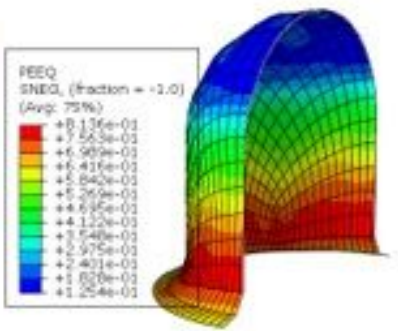

Combination 12

Figure 17 
Equivalent plastic strain distribution map

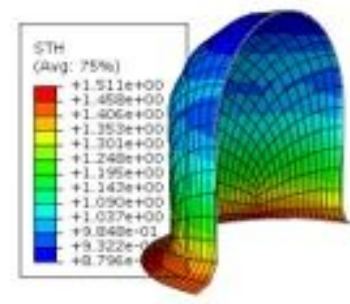

Combination 1

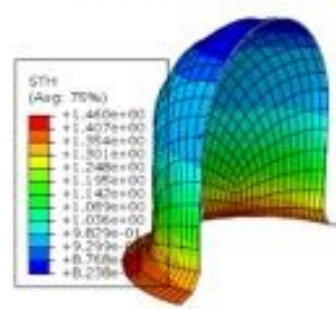

Combination 4

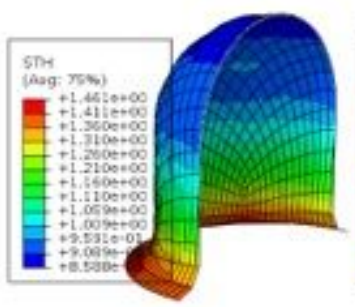

Combination 7

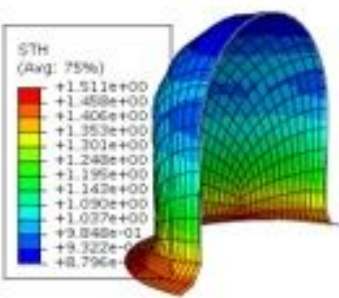

Combination 10

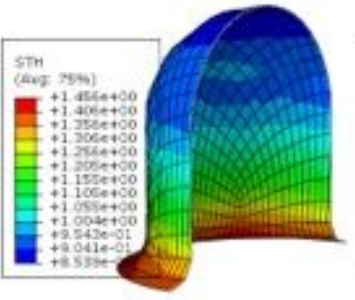

Combination 2

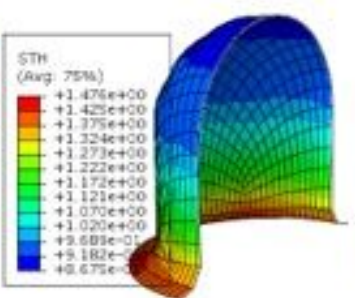

Combination 5

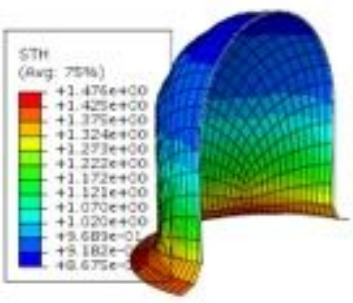

Combination 8

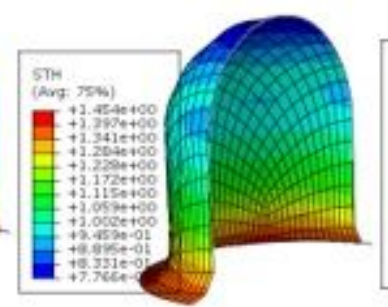

Combination 11

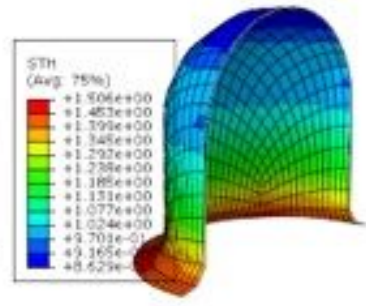

Combination 3

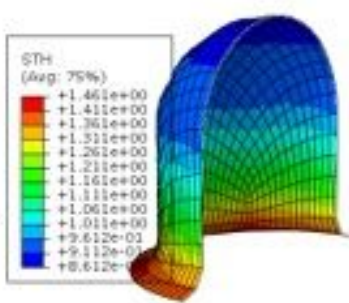

Combination 6

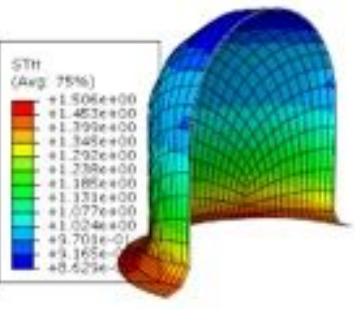

Combination 9

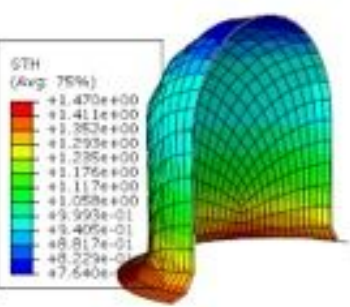

Combination 12

Figure 18

Wall thickness distribution map

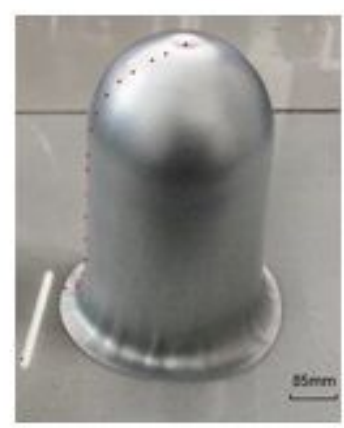

a)

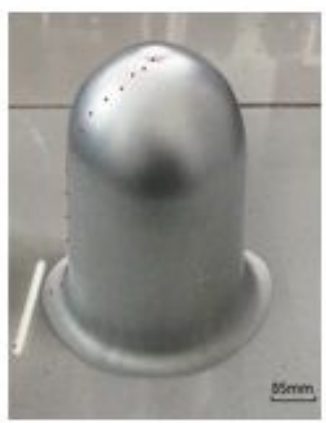

b)

Figure 19 
cylindrical cup with spherical bottom drawing

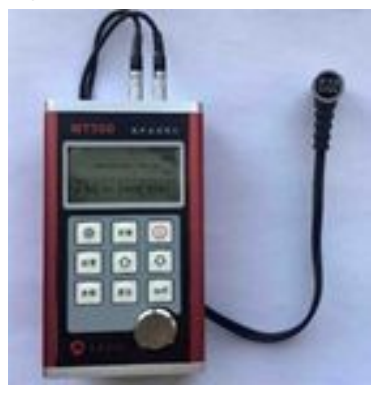

Figure 20

MT500 Ultrasonic Thickness Gauge

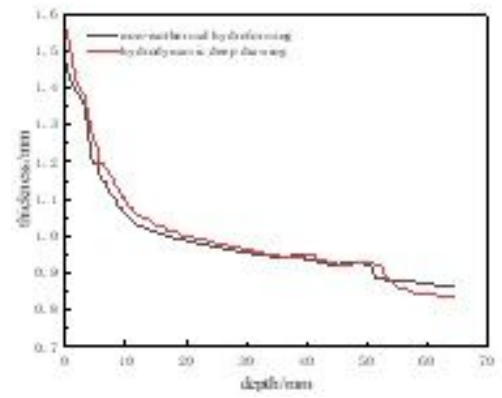

Figure 21

Wall thickness distribution map 